\title{
Article \\ Efficacy of Boron Neutron Capture Therapy in Primary Central Nervous System Lymphoma: In Vitro and In Vivo Evaluation
}

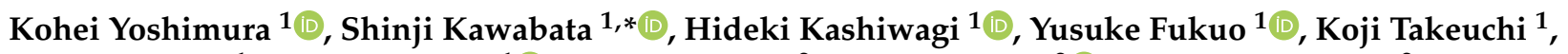 \\ Gen Futamura ${ }^{1}$, Ryo Hiramatsu ${ }^{1}{ }^{\mathbb{D}}$, Takushi Takata ${ }^{2}$, Hiroki Tanaka ${ }^{2}{ }^{(0}$, Tsubasa Watanabe ${ }^{2}$, Minoru Suzuki ${ }^{2}{ }^{\circledR}$, \\ Naonori $\mathrm{Hu}^{3}$, Shin-Ichi Miyatake ${ }^{3}$ and Masahiko Wanibuchi ${ }^{1}$ \\ 1 Department of Neurosurgery, Osaka Medical and Pharmaceutical University, 2-7 Daigaku-Machi, \\ Takatsuki 569-8686, Japan; kohei.yoshimura@ompu.ac.jp (K.Y.); hideki.kashiwagi@ompu.ac.jp (H.K.); \\ yusuke.fukuo@ompu.ac.jp (Y.F.); koji.takeuchi@ompu.ac.jp (K.T.); gen.futamura@ompu.ac.jp (G.F.); \\ ryo.hiramatsu@ompu.ac.jp (R.H.); wanibuchi@ompu.ac.jp (M.W.) \\ 2 Institute for Integrated Radiation and Nuclear Science, Kyoto University, 2 Asashiro-Nishi, Kumatori-cho, \\ Sennan 590-0494, Japan; taku-takata@rri.kyoto-u.ac.jp (T.T.); tanaka.hiroki.3e@kyoto-u.ac.jp (H.T.); \\ watanabe.tsubasa.8x@kyoto-u.ac.jp (T.W.); suzuki.minoru.3x@kyoto-u.ac.jp (M.S.) \\ 3 Kansai BNCT Medical Center, Osaka Medical and Pharmaceutical University, 2-7 Daigaku-Machi, \\ Takatsuki 569-8686, Japan; naonori.ko@ompu.ac.jp (N.H.); shinichi.miyatake@ompu.ac.jp (S.-I.M.) \\ * Correspondence: shinji.kawabata@ompu.ac.jp; Tel.: +81-72-63-1221
}

check for updates

Citation: Yoshimura, K.; Kawabata, S.; Kashiwagi, H.; Fukuo, Y.;

Takeuchi, K.; Futamura, G.;

Hiramatsu, R.; Takata, T.; Tanaka, H.; Watanabe, T.; et al. Efficacy of Boron Neutron Capture Therapy in Primary Central Nervous System Lymphoma: In Vitro and In Vivo Evaluation. Cells 2021, 10, 3398. https://doi.org/ 10.3390/cells10123398

Academic Editor: Kei Nakai

Received: 3 November 2021

Accepted: 29 November 2021

Published: 2 December 2021

Publisher's Note: MDPI stays neutral with regard to jurisdictional claims in published maps and institutional affiliations.

Copyright: (c) 2021 by the authors. Licensee MDPI, Basel, Switzerland. This article is an open access article distributed under the terms and conditions of the Creative Commons Attribution (CC BY) license (https:// creativecommons.org/licenses/by/ $4.0 /)$.

\begin{abstract}
Background: Boron neutron capture therapy (BNCT) is a nuclear reaction-based tumor cell-selective particle irradiation method. High-dose methotrexate and whole-brain radiation therapy (WBRT) are the recommended treatments for primary central nervous system lymphoma (PCNSL). This tumor responds well to initial treatment but relapses even after successful treatment, and the prognosis is poor as there is no safe and effective treatment for relapse. In this study, we aimed to conduct basic research to explore the possibility of using BNCT as a treatment for PCNSL. Methods: The boron concentration in human lymphoma cells was measured. Subsequently, neutron irradiation experiments on lymphoma cells were conducted. A mouse central nervous system (CNS) lymphoma model was created to evaluate the biodistribution of boron after the administration of borono-phenylalanine as a capture agent. In the neutron irradiation study of a mouse PCNSL model, the therapeutic effect of BNCT on PCNSL was evaluated in terms of survival. Results: The boron uptake capability of human lymphoma cells was sufficiently high both in vitro and in vivo. In the neutron irradiation study, the BNCT group showed a higher cell killing effect and prolonged survival compared with the control group. Conclusions: A new therapeutic approach for PCNSL is urgently required, and BNCT may be a promising treatment for PCNSL. The results of this study, including those of neutron irradiation, suggest success in the conduct of future clinical trials to explore the possibility of BNCT as a new treatment option for PCNSL.
\end{abstract}

Keywords: boron neutron capture therapy (BNCT); malignant brain tumor; primary central nervous system lymphoma (PCNSL); radiation therapy

\section{Introduction}

Boron neutron capture therapy (BNCT) is a nuclear reaction-based tumor cell-selective particle irradiation that selectively destroys tumor cells and has been clinically applied as a treatment for invasive cancers, such as high-grade meningiomas [1] and gliomas [2-4]. In BNCT, a boron compound is delivered directly to the tumor cells prior to the therapy, which accumulates in the tumor cells. Subsequent neutron irradiation results in the capture of boron-10 $\left({ }^{10} \mathrm{~B}\right)$ atoms by thermal neutrons to produce high linear energy transfer particles (alpha particles and ${ }^{7} \mathrm{Li}$ recoil nuclei). Because these particles have a short path length (5-9 $\mu \mathrm{m})$, and their path length roughly corresponds to the size of a single tumor cell $(10 \mu \mathrm{m})$, they only destroy B-containing cells. Owing to its limited effect within a single cell, 
it can selectively destroy tumor cells and preserve normal cells. According to the World Health Organization, primary central nervous system lymphoma (PCNSL) is a grade IV malignant brain tumor that accounts for approximately $5 \%$ of all brain tumors in Japan. PCNSL is a common disease in older adults, and $62 \%$ of patients with this tumor are aged $>60$ years [2,3]. The number of patients with PCNSL has increased in recent years [4]. The prognostic factors for PCNSL are age and general performance status [5], and the 2-year survival rate ranges from $50 \%$ to $80 \%$ to $15 \%$ in the malignant group [6]. The treatment strategies for PCNSL are selected based on the results of the biopsy, which are used to confirm the pathological diagnosis of the tumor, and include chemotherapy with high-dose methotrexate (HD-MTX) and whole-brain radiation therapy (WBRT). PCNSL has a very high response rate to initial therapy, but relapse and recurrence occur in almost all patients. Because of the overlap of adverse events associated with the initial therapy, only a few effective treatments are available for recurrent PCNSL; therefore, the prognosis of recurrent PCNSL is poorer. In a previous study using lymphoma cells, lymphoma cells showed a higher sensitivity to photon radiation than other cancer cell types and that the cytotoxicity of BNCT was higher than that of photon irradiation [7]. Therefore, the high cell selectivity and therapeutic effect of BNCT could be expected in patients with refractory and recurrent PCNSL. This is because this cell-selective irradiation treatment can be combined safely with radiotherapy or delivered as a re-irradiation method [8]. To explore the therapeutic application of BNCT for PCNSL, we aimed to conduct a basic study on BNCT using a human lymphoma cell line and a mouse central nervous system (CNS) lymphoma brain tumor model and to evaluate the efficacy and safety of BNCT for PCNSL. This is the first study to evaluate the efficacy of in vivo BNCT for PCSNL.

\section{Materials and Methods}

\subsection{Cell Culture}

Raji and RL human lymphoma cell lines have been histologically characterized as human Burkitt's lymphoma. The Raji lymphoma cells and RL cells were purchased from the Japanese Collection of Research Bioresources and American Type Culture Collection, respectively. Roswell Park Memorial Institute (RPMI) 1640 medium containing 10\% fetal bovine serum (FBS) and 1\% penicillin-streptomycin were used for cell cultures. The cells were grown at $37^{\circ} \mathrm{C}$ in a humidified incubator with $5 \% \mathrm{CO}_{2}$ until they reached confluence. Cell viability was determined by trypan blue dye staining. Cultures with more than $90 \%$ cell viability were used in this study. All materials for cell culture were purchased from Gibco Invitrogen (Grand Island, NY, USA).

\subsection{Borono-Phenylalanine}

4-Borono-L-phenylalanine (BPA) (L-isomer), which was used as a boron carrier in this study, was kindly supplied by Stella Pharma (Osaka, Japan) and converted to a fructose complex [9]. The BPA used in this study was ${ }^{10} \mathrm{~B}$ enriched ( $96 \%$ enriched in ${ }^{10} \mathrm{~B}$ atoms).

\subsection{Boron Uptake in Human Lymphoma Cells}

In this study, we examined whether exposure to BPA resulted in boron uptake into the human lymphoma cells, Raji and RL. First, $1 \times 10^{5}$ Raji and RL cells / $\mathrm{mL}$ were seeded in 100-mm dishes (Becton, Dickinson, and Company, Franklin Lakes, NJ, USA) at $37^{\circ} \mathrm{C}$ in a $5 \% \mathrm{CO}_{2}$ atmosphere using the culture medium described above. After 1 day of incubation at $37^{\circ} \mathrm{C}$, the medium was replaced with a culture medium containing 5,10 , and $20 \mu \mathrm{g}$ $\mathrm{B} / \mathrm{mL}$ of BPA, followed by incubation at $37^{\circ} \mathrm{C}$ for $3 \mathrm{~h}$. The medium containing BPA was removed, and the dishes were washed twice with phosphate-buffered saline (PBS). Then, PBS was added and centrifuged twice to count and sediment the cells. The cells were then lysed overnight in a $1 \mathrm{~N}$ nitric acid solution. The boron concentration in the cells was measured by inductively coupled plasma atomic emission spectroscopy (ICP-AES; Hitachi, Tokyo, Japan). 


\subsection{Photon Irradiation Study of Human Lymphoma Cells}

In this study, we calculated the cell viability ratio of two types of human lymphoma cells, Raji and RL, after photon irradiation to investigate the effect of photon radiation. Specifically, the lymphoma cells, Raji and RL, were cultured for 3 days each and then irradiated at dose rates of 2, 4, 8, 12, 16, and 32 Gy using a photon radiation device (M150WE; SOFTEX, Tokyo, Japan). After photon irradiation, the human lymphoma cells were seeded in 96-well plates at $1.0 \times 10^{5}$ cells/well. After $96 \mathrm{~h}$ of incubation at $37^{\circ} \mathrm{C}$, the cell viability ratio was calculated using the water-soluble tetrazolium-8 (WST-8) assay with a Cell Counting Kit-8 (CCK-8, Dojindo, Kumamoto, Japan). The cell viability ratio was calculated using a modified version of the manufacturer-provided protocols [10] and according to Equation (1):

Cell viability ratio $(\%)=($ absorbance value of irradiated cell/absorbance value of untreated cells $) \times 100$

\subsection{Neutron Irradiation Study of Human Lymphoma Cells}

In this study, the lymphoma cells, Raji and RL, were cultured for several days and then exposed to BPA for $3 \mathrm{~h}$, followed by neutron irradiation for 0,15 , and $30 \mathrm{~min}$ in a research reactor in KURNS. Neutron irradiation was performed at a reactor power of $1 \mathrm{MW}$ and neutron flux of $6.0 \times 10^{8}$ neutrons $/ \mathrm{cm}^{2} / \mathrm{s}$ for 15 and $30 \mathrm{~min}$. The physical dose values of thermal, epithermal, fast neutrons, and $\gamma$ rays, respectively, in this irradiation of 15 and $30 \mathrm{~min}$ were $0.11,0.02,0.11$, and $0.2 \mathrm{~Gy}$ for a total of $0.5 \mathrm{~Gy}$ and $0.24,0.03,0.18$, and $0.72 \mathrm{~Gy}$ for a total of $1.2 \mathrm{~Gy}$. The concentrations of BPA administered were 5,10 , and $20 \mu \mathrm{g} / \mathrm{mL}$. After neutron irradiation, the cells were collected and plated at $1.0 \times 10^{5}$ cells/well in 96-well plates. After $96 \mathrm{~h}$ of incubation at $37^{\circ} \mathrm{C}$, the cell viability ratio was measured using the WST- 8 assay with CCK- 8 . The cell viability ratio was calculated by modifying the protocol provided by the manufacturer and further corrected based on the results of the photon irradiation study.

\subsection{Mouse CNS Lymphoma Model}

All animal studies were performed in accordance with the Guide for the Care and Use of Laboratory Animals and approved by the Animal Use Review Board and Ethical Committee of Osaka Medical College (permit no. 2020-107) and the Institute for Integrated Radiation and Nuclear Science, Kyoto University (KURNS; Kumatori, Osaka, Japan) (permit no. 2020-31). The animals used for the study were eight-week-old male BALB/c $\mathrm{nu} /$ nu mice (Japan SLC; Shizuoka, Japan). Each mouse was anesthetized by an intraperitoneal injection of a mixture of three different anesthetic agents: medetomidine (ZENOAQ, Fukushima, Japan) $(0.4 \mathrm{mg} / \mathrm{kg})$, midazolam (Sandoz, Yamagata, Japan) $(2.0 \mathrm{mg} / \mathrm{kg}$ ), and butorphanol (Meiji Seika, Tokyo, Japan) $(5.0 \mathrm{mg} / \mathrm{kg})$. The animal's head was fixed with a stereotactic frame (IMPACT-1000C + MA-625, Muromachi Kikai, Tokyo, Japan). The Raji lymphoma cells were surgically implanted into the mouse brain using a technique that was previously adopted by our research group to confirm the efficacy of a novel boron compound. The Raji lymphoma cells were diluted in a $10 \mu \mathrm{L}$ solution of RPMI containing 1.4\% agarose (Wako Pure Chemical Industries, Osaka, Japan) at a concentration of $2.0 \times 10^{5}$ cells and were injected at a rate of $20 \mu \mathrm{L} / \mathrm{min}$ using an automatic infuser pump. The mice were implanted with Raji lymphoma cells in the brain and sacrificed when the endpoint was reached. The microscopic examination of the mouse brain revealed that the tumors had formed in the intracerebral region. The histopathological evaluation showed lymphoma cells in the brain parenchyma, with the diffuse proliferation of small blasts similar to human PCNSL (Figure A1). In this CNS lymphoma model using the Raji human lymphoma cell line, tumor engraftment was achieved, and the model was determined to be suitable for further therapeutic studies to evaluate the effect of BNCT. 


\subsection{In Vivo Biodistribution Study}

After tumor implantation, when the mice showed signs of tumor growth (i.e., weight loss, lethargy, hunching, and ataxia), in vivo biodistribution studies were initiated. BPA was administered to the mouse CNS lymphoma model at doses equivalent to those of boron and was eventually adjusted to $24 \mathrm{mg} \mathrm{B} / \mathrm{kg}$ body weight (b.w.). Three hours later, the mice were euthanized, and the tumor, brain, blood, heart, lung, liver, spleen, kidney, and skin were removed and weighed. The amount of boron in each organ was quantified by ICP-AES.

\subsection{In Vivo Irradiation Study}

Neutron irradiation studies were performed to investigate the therapeutic effect of neutron irradiation after BPA administration in the Raji mouse CNS lymphoma model. The mice transplanted with $2.0 \times 10^{5}$ Raji lymphoma cells were treated with neutron irradiation at KURNS. Neutron irradiation was performed at a reactor power of $1 \mathrm{MW}$ and neutron flux of $8.1 \times 10^{8}$ neutrons $/ \mathrm{cm}^{2} / \mathrm{s}$ for 15 and $30 \mathrm{~min}$. Thirty-five mouse CNS lymphoma models were randomly divided into five groups. Irradiation was performed $3 \mathrm{~h}$ after the intraperitoneal administration of BPA (24 mg B/ $\mathrm{kg}$ b.w.).

- Group 1: Untreated control

- Group 2: BPA only

- Group 3: Neutron irradiation only

- Group 4: 15min of neutron irradiation following BPA administration (BNCT 15-min group)

- Group 5: 30min of neutron irradiation following BPA administration (BNCT 30-min group)

After the animals were anesthetized using a mixture of the abovementioned anesthetic agents, their bodies (except for the head) were covered with ${ }^{6} \mathrm{LiF}$ ceramic tiles to protect the thermal neutrons in order to reduce whole-body exposure to radiation. Neutron irradiation was performed $3 \mathrm{~h}$ after BPA administration. After the neutron irradiation study, the mouse CNS lymphoma model was left at KURNS. The survival time of the mice in all the groups was used to evaluate the treatment effect. Based on the MST, we calculated and evaluated the percentage of increased lifespan (\%ILS) for each group relative to the untreated control, as reported in our previous studies [11].

\subsection{Statistical Analysis}

Statistical analyses were performed using the JMP Pro 15 software (SAS Institute Inc., Cary, NC, USA). Student's $t$-test was performed to compare the cell viability ratio. A log-rank test was performed to test the equality of survival curves of in vivo irradiation study. Finally, a $p$-value of less than 0.05 was considered significant.

\section{Results}

\subsection{Boron Uptake in Human Lymphoma Cells}

The cellular boron concentrations obtained using BPA, incubated with 5, 10, and $20 \mu \mathrm{g} \mathrm{B} / \mathrm{mL}$, are shown in the graph (Figure 1). In $5 \mu \mathrm{g} \mathrm{B} / \mathrm{mL}$ BPA, both Raji and RL showed high concentrations ( $64.4 \pm 4.7$ and $71.4 \pm 2.5 \mu \mathrm{g} \mathrm{B} / 10^{9}$ cells). Even in $10 \mu \mathrm{g} \mathrm{B} / \mathrm{mL}$ of BPA, both Raji and RL showed high concentrations $(107 \pm 14.4$ and $108.4 \pm 7.6 \mu \mathrm{g}$ $\mathrm{B} / 10^{9}$ cells). Meanwhile, $20 \mu \mathrm{g} \mathrm{B} / \mathrm{mL}$ of BPA showed similar results $(187.5 \pm 7.9$ and $205.7 \pm 8.4 \mu \mathrm{g} \mathrm{B} / 10^{9}$ cells).

\subsection{Photon Irradiation Study of Human Lymphoma Cells}

The cell viability ratio at $96 \mathrm{~h}$ after photon irradiation is shown in Figure 2. In Raji cells, the cell viability ratio decreased when the irradiation dose was increased from $2 \mathrm{~Gy}$ to $32 \mathrm{~Gy}$ $(0.62 \pm 0.07,0.58 \pm 0.07,0.28 \pm 0.06,0.19 \pm 0.03,0.19 \pm 0.04$, and $0.13 \pm 0.03)$. A statistically significant decrease in the cell viability ratio was observed at $2 \mathrm{~Gy}(p=0.0008)$, and the same observation was reported when the irradiation dose was increased to $32 \mathrm{~Gy}$. The $p$-values from 4 to 32 Gy were as follows: $p=0.0004,0.00002,0.00004,0.00001$, and 0.00002 . In RL cells, the cell viability ratio decreased when the irradiation dose was increased from 
2 to $32 \mathrm{~Gy}(0.72 \pm 0.03,0.33 \pm 0.02,0.23 \pm 0.01,0.17 \pm 0.007,0.14 \pm 0.01$, and $0.18 \pm 0.01)$ and showed a significant difference $(p=0.02)$. The $p$-values from 4 to $32 \mathrm{~Gy}$ were as follows: $p=0.0007,0.0005,0.0004,0.0002$, and 0.0001 .

250

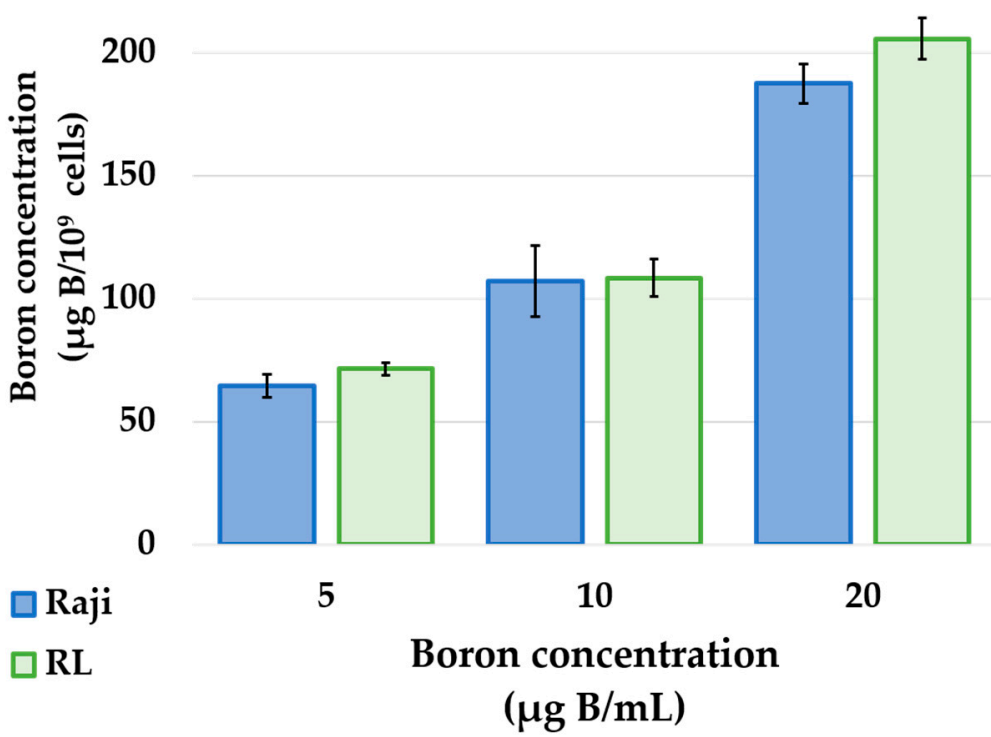

Figure 1. Cellular uptake of boron in human lymphoma cells. Boron concentration of Raji (blue) and RL (green) lymphoma in RPMI 1640, using 5, 10, and $20 \mu \mathrm{g} \mathrm{B} / \mathrm{mL}$ of BPA for $3 \mathrm{~h}$. The boron concentration of lymphoma cells was high for both Raji and RL.

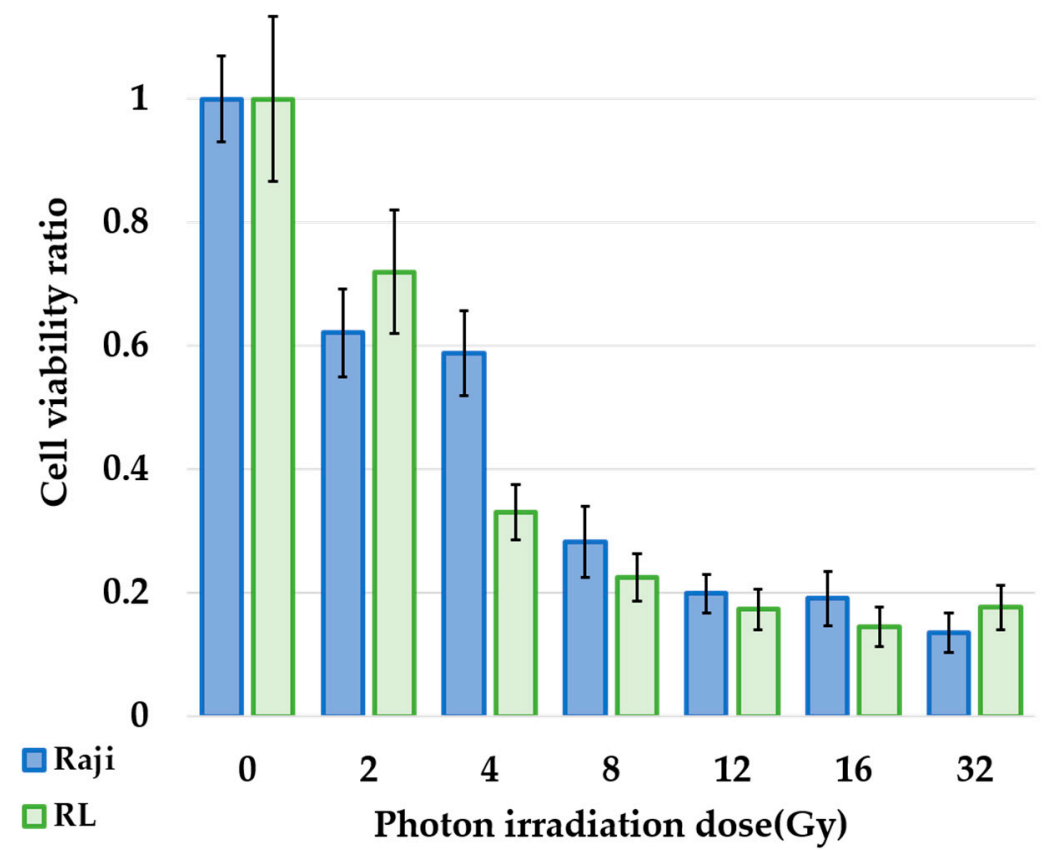

Figure 2. Relationship between cell viability ratio and photon radiation dose. The cell viability ratio of lymphoma cells after 96 h of irradiation from 0 to $32 \mathrm{~Gy}$. Cell viability ratio of Raji cells are shown in blue, and that of RL are shown in green. There was a significantly decreased cell viability ratio by more than 2 Gy irradiation compared to 0 Gy in Raji and RL $(p<0.05)$. 


\subsection{Neutron Irradiation Study of Human Lymphoma Cells}

The cell viability ratio at $96 \mathrm{~h}$ after neutron irradiation is shown in Figure 3. BNCT after $5 \mu \mathrm{g} \mathrm{B} / \mathrm{mL}$ exposure significantly reduced the cell viability ratio in Raji lymphoma cells compared with that in controls $(0.23 \pm 0.07$ vs. $1.00 \pm 0.13, p=0.0001)$, and the same result was observed in RL ( $0.33 \pm 0.01$ vs. $1.00 \pm 0.02$ vs. $p=0.02)$. The results were similar for both Raji and RL at other concentrations: $10 \mu \mathrm{g} \mathrm{B} / \mathrm{mL}(0.12 \pm 0.03 ; p=0.0004$ and $0.29 \pm 0.02 ; p=0.04)$ and $20 \mu \mathrm{g} \mathrm{B} / \mathrm{mL}(0.14 \pm 0.03 ; p=0.0003$ and $0.25 \pm 0.04 ; p=0.01)$.

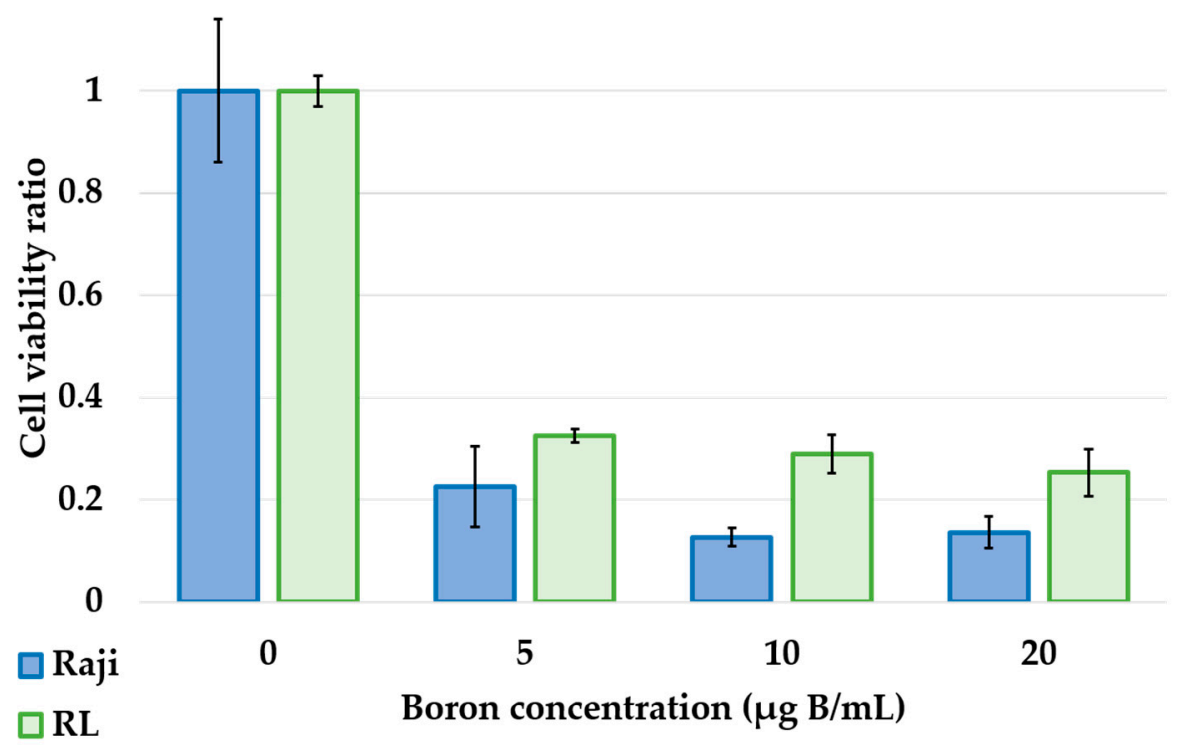

Figure 3. Relationship between boron concentration and cell viability ratio after neutron irradiation. Cell viability of lymphoma cells after exposure to BPA at concentrations of 5, 10, and $20 \mu \mathrm{g} \mathrm{B} / \mathrm{mL}$ for $3 \mathrm{~h}$ followed by irradiation with $1 \mathrm{MW}$ neutrons for $30 \mathrm{~min}$ and incubation for $96 \mathrm{~h}$. Blue is Raji lymphoma cells, and green is RL lymphoma cells. In Raji lymphoma cells. BNCT significantly reduced the cell viability of lymphoma cells $(p<0.05)$.

\subsection{In Vivo Biodistribution Study}

The boron concentrations in the tumor, brain, blood, and other organs were measured. The boron concentrations in the tumor, brain, and blood were $9.9 \pm 1.6,3.5 \pm 1.8 \mu \mathrm{g} / \mathrm{g}$, and $13.8 \pm 3.5 \mu \mathrm{g} / \mathrm{mL}$, respectively, and the boron concentration in the tumor was significantly higher than that in the brain $(p=0.0006)$. The tumor to normal brain (contralateral brain) ratio was 2.84 , while the tumor to blood ratio was 0.72 . Other organs, such as the heart, lungs, liver, kidney, spleen, and skin, were also measured, and results showed the accumulation of boron $(13.0 \pm 2.8,19.4 \pm 6.4,14.4 \pm 6.2,53.2 \pm 17.4,23.6 \pm 8.0$, and $18.7 \pm 9.4 \mu \mathrm{g} / \mathrm{g})$. The data are summarized in Figure 4.

\subsection{In Vivo Irradiation Study}

The Kaplan-Meier survival curves for the mouse CNS lymphoma model that underwent neutron irradiation are shown in Figure 5. The MST durations for the control group (untreated control, BPA only, neutron irradiation only) and the BNCT group (BNCT 15-min or BNCT 30-min) were 26.5 (range: 21-39 days), 31.5 (28-39 days), 31 (22-33 days), 44 (33-36 days), and 39 days (36-40 days). The survival time was significantly longer in the BNCT 30-min group $(p=0.007)$ than in the untreated control group and between the BNCT 15 -min group and the untreated control group $(p=0.02)$. In addition, the BNCT 30-min group showed the highest \%ILS value among all groups (66.0\%). The \%ILS values for the other groups (BPA only, neutron only, and BNCT $15-\mathrm{min}$ ) were $17.0 \%, 18.9 \%$, and $47.2 \%$, respectively (Table 1). 


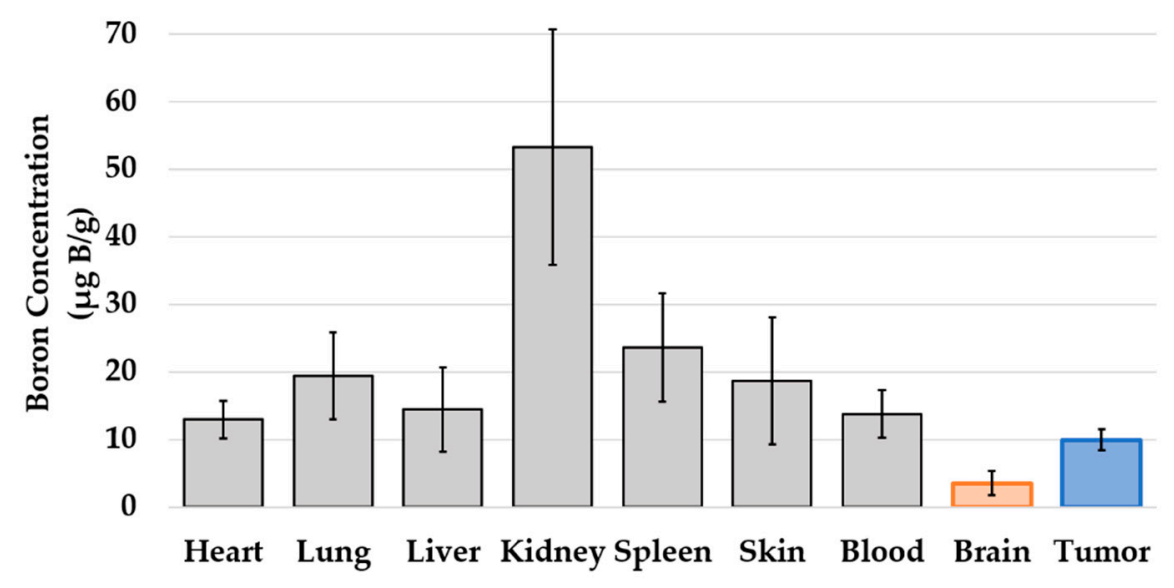

Figure 4. Boron concentrations in various organs of mouse CNS lymphoma models treated with BPA. Tumors had significantly higher boron concentrations $(9.9 \pm 1.6 \mu \mathrm{g} / \mathrm{g})$ compared to the brain $(3.5 \pm 1.8 \mu \mathrm{g} / \mathrm{g}: p<0.05)$. The tumor to brain ratio $(: \mathrm{T} / \mathrm{Br})$ was 2.85 . The tumor to blood ratio (: $\mathrm{T} / \mathrm{Bl})$ was 0.72 . Boron accumulation was also observed in other organs.

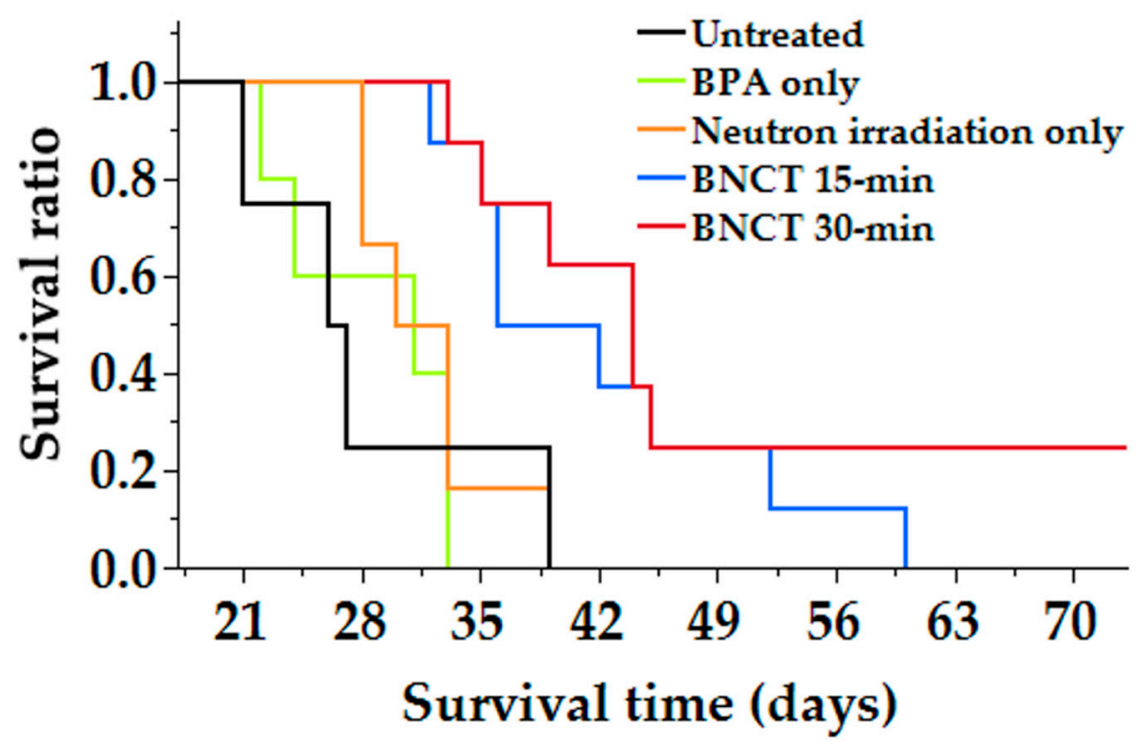

Figure 5. Kaplan-Meier survival curves of mouse CNS lymphoma models after neutron irradiation. Survival times in days after tumor implantation were plotted for the following groups: untreated control (black line), BPA only (green line), neutron irradiation only (orange line), BNCT 15-min: BPA exposure followed by 15 min of neutron irradiation (blue line), and BNCT 30-min: BPA exposure followed by $30 \mathrm{~min}$ of neutron irradiation (brown line). Median survival times of untreated control group, BPA only group, Neutron irradiation only group, BNCT 15-min group, and BNCT 30-min group were $28.2 \pm 3.8,28.6 \pm 2.3,31.8 \pm 1.7,42.3 \pm 3.4$, and $41.3 \pm 1.8$ days. There were statistically significant differences between the BNCT 30-min group and untreated control group $(p=0.007)$ and between the BNCT 15-min group and untreated control group $(p=0.02)$. 
Table 1. Survival times of mouse CNS lymphoma models after neutron irradiation.

\begin{tabular}{|c|c|c|c|c|c|c|}
\hline \multirow{2}{*}{ Group } & \multirow{2}{*}{ Irradiation Time (min) } & \multirow{2}{*}{$n^{1}$} & \multicolumn{3}{|c|}{ Survival Time } & \multirow{2}{*}{$\begin{array}{c}\text { oILS }^{2} \\
\text { Median }\end{array}$} \\
\hline & & & Mean \pm SD & Median & Range & \\
\hline $\begin{array}{l}\text { Untreated } \\
\text { control }\end{array}$ & 0 & 6 & $28.2 \pm 3.8$ & 26.5 & $23.5-33$ & \\
\hline BPA only & 0 & 6 & $28.6 \pm 2.3$ & 31 & $24-33$ & $17.0 \%$ \\
\hline $\begin{array}{c}\text { Neutron } \\
\text { irradiation only }\end{array}$ & 30 & 8 & $31.8 \pm 1.7$ & 31.5 & $28-33$ & $18.9 \%$ \\
\hline BNCT 15-min & 15 & 7 & $42.3 \pm 3.4$ & 39 & $35.5-48.5$ & $47.2 \%$ \\
\hline BNCT 30-min & 30 & 8 & $41.3 \pm 1.8$ & 44 & $37-$ & $66.0 \%$ \\
\hline
\end{tabular}

${ }^{1}$ Number of animals. ${ }^{2}$ Percent increased life span (\%ILS) was defined relative to the mean survival times of untreated controls.

\section{Discussion}

The results of in vitro boron uptake studies showed that both human lymphoma cell lines, Raji and RL, showed a concentration-dependent increase in cellular boron uptake upon exposure to BPA (Figure 1). BPA is taken up into the cells via the L-type amino acid transporter 1 (LAT1), an amino acid transporter specifically expressed in cancer cells [12]. In addition, previous studies have shown that tumor cells from PCNSL express high levels of LAT1 [13]. Based on these facts and the results of this study, BPA is a suitable boroncarrying drug used in BNCT for the treatment of PCNSL and that a high concentration of BPA in the tumor would result in a higher therapeutic effect.

Photon irradiation studies showed that lymphoma cells, Raji and RL, showed dosedependent cytotoxicity and high radiosensitivity (Figure 2). The neutron irradiation study showed a significant decrease in the cell viability ratio after neutron irradiation and BPA exposure (Figure 3). This result proved that in lymphoma cells, the cell viability ratio was significantly reduced by BNCT in vitro. However, despite the increase in cellular boron concentration in the in vitro boron uptake study (Figure 1), a concentration-dependent decrease in cell viability ratio was not observed in the neutron irradiation study (Figure 3). Based on these results, we considered that the concentration of boron administered and the concentration of boron actually taken up into the cells were different. Actually, it has been reported that the uptake of BPA differs depending on the cell cycle [14]. We estimated the biological photon equivalent dose (equivalent dose) in the in vitro neutron irradiation studies and calculated the combined biological effectiveness (CBE) value of BPA in each lymphoma cell. Specifically, a logistic regression analysis of the photon irradiation study results was performed. The equivalent dose in the neutron irradiation study was estimated by applying the cell survival rate of neutron irradiation to the results of the logistic analysis of photon irradiation. The calculated CBE value of the boron compounds was calculated by applying the estimated equivalent dose to the following equation, which has been proposed in many previous studies. $\mathrm{D}_{\mathrm{B}}$ is the physical dose of boron derived from Equation (2). The relative biological effectiveness (RBE) for nitrogen $\left(R_{B E}\right)$ value was 3.0, and that for hydrogen $\left(\mathrm{RBE}_{\mathrm{H}}\right)$ value was also 3.0 [15].

Photon equivalent dose $(\mathrm{Gy}-\mathrm{Eq})=\mathrm{D}_{\mathrm{B}} \times \mathrm{CBE}+\mathrm{D}_{\mathrm{N}} \times \mathrm{RBE}_{\mathrm{N}}+\mathrm{D}_{\mathrm{H}} \times \mathrm{RBE}_{\mathrm{H}}+\mathrm{D}_{\gamma}$

$7.43 \times 10^{-14}\left(\mathrm{~Gy} \mathrm{~cm}^{2} / \mu \mathrm{g} \mathrm{B} / \mathrm{g}\right) \times$ boron concentration $(\mu \mathrm{g} \mathrm{B} / \mathrm{g}) \times$ thermal neutron fluence $\left(1 / \mathrm{cm}^{2}\right)$. DN is the physical dose of nitrogen derived from the equation $6.78 \times$ $10^{-14}\left(\mathrm{~Gy} \mathrm{~cm}^{2} /\right.$ weight $\left.\%\right) \times$ nitrogen concentration (weight $\left.\%\right) \times$ thermal neutron fluence $\left(1 / \mathrm{cm}^{2}\right)$. D $\gamma$ is the physical dose of gamma radiation. These values were obtained from a previous study [16]. In this study, the $\mathrm{DN}$ value was 0.43 , the $\mathrm{DH}$ value was 0.24 , and the D $\gamma$ value was 0.72 . The calculated CBE value to a boron concentration of $5 \mu \mathrm{g} \mathrm{B} / \mathrm{mL}$ in Raji cells was 10.6, with an estimated equivalent dose value (photon-equivalent dose; Gy-Eq) of 11.2. The equivalent doses of 10 and $20 \mu \mathrm{g} \mathrm{B} / \mathrm{mL}$ in Raji cells could not be estimated due to deviations from the results of the logistic analysis. The calculated CBE value to a boron concentration of $5 \mu \mathrm{g} \mathrm{B} / \mathrm{mL}$ in RL cells was 5.6 with an equivalent dose value of 7.2 (Gy-Eq), 
the calculated CBE value to a boron concentration of $10 \mu \mathrm{g} \mathrm{B} / \mathrm{mL}$ was 3.4 with an estimated equivalent dose value of $5.4(\mathrm{~Gy}-\mathrm{Eq})$, and the calculated $\mathrm{CBE}$ value to a boron concentration of $20 \mu \mathrm{g} \mathrm{B} / \mathrm{mL}$ was 2.0 with an estimated equivalent dose value of 6.4 (Gy-Eq). In RL cells, the equivalent dose did not increase in a boron concentration-dependent manner, and the estimated CBE values decreased. There are two reasons for this result (a) if the cells were washed with PBS and placed in the medium without boron for irradiation, BPA leaked from the cells, and there was no or little boron in the cells during neutron irradiation; therefore, the results were pretty much the same for all boron concentration groups; (b) the neutron beam was contaminated with gamma rays and fast neutrons to the extent where boron neutron capture reaction result was masked or hidden in the more prominent effect of the beam components. This finding suggests that the CBE values estimated in this study may not be accurate. The CBE value of gliomas currently using BNCT in clinical practice is 3.8 [17]; by contrast, the CBE value of lymphomas estimated in this study was higher than that value. The two types of lymphoma cells used in this study were floating cells, so we could not perform the colony formation assay typically used to study the effects of photon irradiation. Therefore, we compared the results of the photon irradiation and neutron irradiation studies by correcting for cell viability as measured by the WST-8 assay. As a supplement, fitting graphs of the linear-quadratic (LQ) model using the cell viability obtained by the WST-8 assay are shown in the Appendix (Figure A2). BNCT for lymphoma caused a decrease in the cell viability ratio. Therefore, we believe that this study demonstrates the major advantage of BNCT for PCNSL in vitro.

In this study, we performed in vitro cell studies using Raji and RL cells. We created a mouse CNS lymphoma model using Raji cells, which has been previously reported in mouse CNS lymphoma models. Mouse CNS lymphoma models have been used in various studies [18], and other lymphoma models have been established in previous studies. Wang et al. created a CNS lymphoma model using Raji cells similar to the one we used in this study and showed that celecoxib prolonged their survival [19]. Since the RL cells showed good boron uptake in vitro and BNCT showed a significant decrease in cell viability, in vivo irradiation studies were not performed. We created a mouse CNS lymphoma model using RL cells, but the tumor implantation rate was low. Hence, the model was not used in the study as we thought it was unsuitable for neutron irradiation studies using a small number of animal models in the limited environment of a nuclear reactor.

The biodistribution in the mouse CNS lymphoma model showed that a higher BPA concentration was taken up in the tumor than in the normal brain (Figure 4). Other organs also showed BPA uptake, and the highest uptake values were found in the kidneys. Previous studies have shown that BPA is rapidly cleared by the kidneys in mouse models and in clinical human trials [20]. In this study, the kidneys retained high concentrations of BPA, suggesting that the drug was also cleared by the urinary system in the mouse lymphoma model. Neutron irradiation studies using a mouse CNS lymphoma model showed a significant prolongation of survival in the BNCT group compared with the control group, and no significant difference was observed in the neutron irradiation only group (Figure 5). The reason why survival time was prolonged only in the BNCT group and not in the neutron irradiation group was thought to be due to the selective uptake of boron into the tumor, which allowed more equivalent doses to be delivered to the tumor in the BNCT group than in the neutron irradiation only group. This may be due to the fact that tumor-selective boron uptake was obtained in the mouse CNS lymphoma model, as revealed by biodistribution studies. Therefore, we determined the equivalent radiation dose for the mouse CNS model using the CBE value calculated based on the data from the in vitro study (Table 2). 
Table 2. Summary of physical radiation doses and equivalent doses delivered in Raji lymphoma bearing mice.

\begin{tabular}{ccccc}
\hline \multirow{2}{*}{ Group } & \multicolumn{2}{c}{ Physical Dose $^{\mathbf{1}}$} & \multicolumn{2}{c}{ Equivalent Dose $^{2}$} \\
\cline { 2 - 5 } & Brain & Tumor & Brain & Tumor \\
\hline Untreated control & 0 & 0 & 0 & 0 \\
BPA only & 0 & 0 & 0 & 0 \\
Neutron irradiated only & 0.6 & 0.6 & 1.4 & 1.4 \\
BNCT 15-min & 0.3 & 0.3 & 1.0 & 8.8 \\
BNCT 30-min & 0.6 & 0.6 & 2.0 & 16.6 \\
\hline
\end{tabular}

${ }^{1}$ Physical dose estimates include doses from gamma rays, ${ }^{10} \mathrm{~B}(n$, alpha $){ }^{7} \mathrm{Li}^{14} \mathrm{~N}(n, p){ }^{14} \mathrm{C}$, and ${ }^{1} \mathrm{H}(n, n){ }^{1} \mathrm{H}$ reactions

2 The equivalent dose is a value calculated by the equation. $D_{B} \times C B E_{B}+D_{N} \times R E_{N}+D_{H} \times R E_{H}+D_{\gamma}$. $\left(D_{B}\right.$ : Boron dose, $\mathrm{D}_{\mathrm{N}}$ : neutron dose, $\mathrm{D}_{\mathrm{H}}$ : hydrogen dose, $\mathrm{D}_{\gamma}$ : gamma-ray dose). $\mathrm{CBE}_{\mathrm{B}}$ is based on the Compound Biological Effectiveness (CBE) of $\mathrm{D}_{\mathrm{B}}$, and in the case of BPA, this value is 10.6 for tumor tissue and 0.9 for the normal brain. $R_{B} E_{N}$ is based on RBE (Relative Biological Effectiveness) for $D_{N}$, and this value is 3.0. $R B E_{H}$ is based on RBE (Relative Biological Effectiveness) for $\mathrm{D}_{\mathrm{H}}$, and this value is 3.0.

As shown in the table, the equivalent doses delivered to the tumor were 8.8 and 16.6 (Gy-Eq) compared with 1.4 (Gy-Eq), while those delivered to the normal brain were 1.0 and 2.0 (Gy-Eq) compared with 1.4 (Gy-Eq) in the neutron irradiation only and BNCT groups, respectively. This result indicates that the tumor was irradiated with a higher equivalent dose compared to the brain, even though the same neutrons were irradiated, indicating that the tumor-selective treatment of BNCT was indeed achieved.

PCNSL was initially treated with WBRT because of its high sensitivity to photon radiation, but the use of MTX in the 1970s improved the patients' survival [21]. Later, PCNSL was found to be highly sensitive to HD-MTX, and the mainstay of treatment was a combination of HD-MTX and WBRT. The treatment strategies for PCNSL are selected based on the results of the biopsy, which is performed to confirm the pathological diagnosis of the tumor and include chemotherapy using high-dose methotrexate (HD-MTX) and WBRT [22]. The response rate to initial therapy is nearly $90 \%$, and the median survival is approximately 36 months, indicating a good response to initial therapy [23]. However, the recurrence rate is high, and the prognosis of patients with PCNSL who have recurrence is poor, with a median survival of 2 months without additional therapy. Most PCNSL patients are aged $>60$ years; the incidence of leukoencephalopathy is significantly increased when a combination of MTX therapy and WBRT is used in patients aged $>60$ years compared with HD-MTX therapy alone [24,25]. Several studies have also observed a significant decrease in Karnofsky Performance Status and a significant decrease in quality of life (QOL) in older patients after undergoing WBRT $[26,27]$. The mechanism of WBRT-induced neurotoxicity is not yet clear, but it is thought to involve vascular toxicity, demyelination, and depletion of neural progenitor cells from the subventricular zone [28]. PCNSL has a high recurrence rate relative to the initial treatment response rate; therefore, recurrence is inevitable, but effective treatment options for PCNSL that recur after treatment have not yet been established. Additional radiotherapy is not recommended due to the possibility of delayed neurotoxicity. There is no effective treatment for recurrent PCNSL because the use of a combination of two treatments increases the possibility of adverse events; hence, a new treatment must be developed. If boron is selectively distributed to the tumor, BNCT can provide an extremely large equivalent dose to the tumor but a sufficient dose to the normal tissue, which is irradiated with a neutron beam [29]. In other words, it is possible to provide a dose to normal tissues that do not cause adverse events and a sufficient dose to tumors. This property of BNCT is very beneficial for recurrent PCNSL, for which treatment is limited due to the occurrence of adverse events caused by photon irradiation. Therefore, when BNCT is used in the clinical setting, these benefits will be assessed from the treated patients, and we will conduct a clinical trial targeting the treatment of recurrent PCNSL. In addition, since BNCT has high tumor selectivity and excellent local control [30], it can improve the QOL by resolving the clinical symptoms of recurrent PCNSL, such as paralysis. In addition, by performing BNCT as an initial treatment, it is possible to perform HD-MTX 
or WBRT without worrying about the possible occurrence of leukoencephalopathy at the time of recurrence. We believe that brain edema and radiation-induced late effects due to neutron irradiation after photon irradiation may raise a concern when BNCT is performed as a treatment for recurrent PCNSL. With regard to this issue, previous clinical studies on BNCT have not reported any new adverse events due to BNCT when used as a treatment for recurrent glioblastoma after radiotherapy [8]. Of course, it is difficult to compare the different diseases that require treatment; however, we believe that this is one of the reasons why the safety of using BNCT for recurrent PCNSL after radiotherapy. In the future, we will conduct repeat irradiation studies on PCNSL to confirm its efficacy and safety.

Due to the use of a nuclear reactor in this study, neutron irradiation experiments could only be performed $3 \mathrm{~h}$ after BPA administration. Therefore, it is possible that different results could be obtained if the experiments were conducted at different times. In addition, the photon irradiation in this study was performed at a machine with the maximum photon energy of $150 \mathrm{keV}$, which is smaller than the $250 \mathrm{keV}$ of a standard. Therefore, if a different irradiation device is used, the results may differ.

\section{Conclusions}

We performed basic research on BNCT using a mouse CNS lymphoma brain tumor model and a human lymphoma cell line. This study suggests that BNCT could potentially be a promising treatment for PCNSL and showed a high possibility of contributing to the future development of PCNSL treatment and BNCT.

Author Contributions: Conceptualization, S.K.; methodology, K.Y., H.K., Y.F., G.F. and S.K.; formal analysis, investigation, and data curation, K.Y., H.K., T.T., H.T. and T.W.; resources, K.Y., H.K., Y.F., G.F., R.H., T.T. and H.T.; writing—original draft preparation, K.Y. and K.T.; writing—review and editing, N.H., S.K. and H.T.; supervision, M.W., S.-I.M. and M.S.; project administration and funding acquisition, K.T. and S.K. All authors have read and agreed to the published version of the manuscript.

Funding: This research was funded by JSPS KAKENHI Grant-in-Aid for Research Activity Start-up (19K24055) to K.T. and partly by Grants-in-Aid for Scientific Research (B) to S.K. (20H03797) from the Japan Society for the Promotion of Science (JSPS). All authors declare that they have no conflict of interest.

Institutional Review Board Statement: The study was conducted according to the guidelines of the Declaration of Helsinki, and approved by the Animal Use Review Board and Ethical Committee of Osaka Medical College (permit no. 2020-107, 27 January 2021) and the Institute for Integrated Radiation and Nuclear Science, Kyoto University (KURNS; Kumatori, Osaka, Japan) (permit no. 2020-31, 3 February 2021).

Informed Consent Statement: Not applicable.

Data Availability Statement: The data that support the findings of this study are available from the corresponding author, S.K., upon reasonable request.

Acknowledgments: The authors thank Aya Sunamura for her secretarial work and Itsuko Inoue for her technical assistance.

Conflicts of Interest: The authors declare no conflict of interest. 


\section{Appendix A}

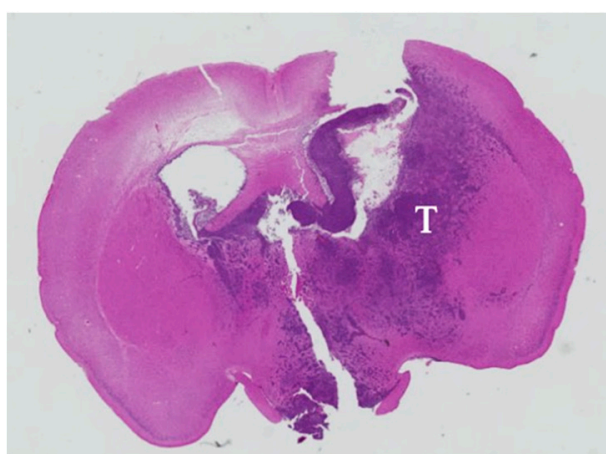

(a)

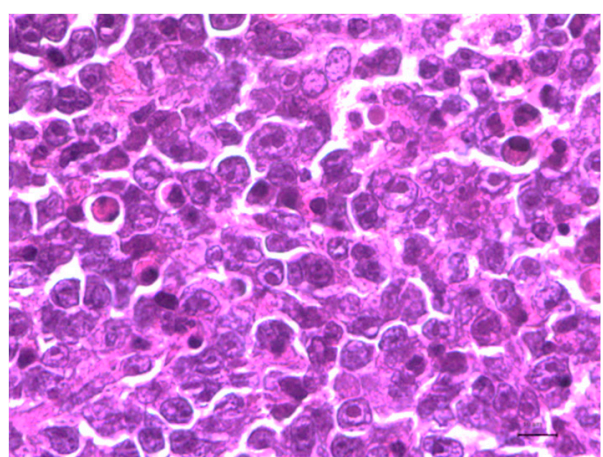

(b)

Figure A1. Representative aspect of CNS lymphoma sections stained with hematoxylin-Eosin (HE). (a): Photomicrographs of brain parenchyma after Raji lymphoma cells implantation. The mice were sacrificed when the body weight was reduced by $25 \%$. The brain was removed and sectioned serially. The character $\mathrm{T}$ in the figure represents tumor formation $(\times 4)$. $(\mathbf{b})$ : Perivascular cuffing and diffuse proliferation of microblasts typical of lymphomas is seen $(\times 100)$.

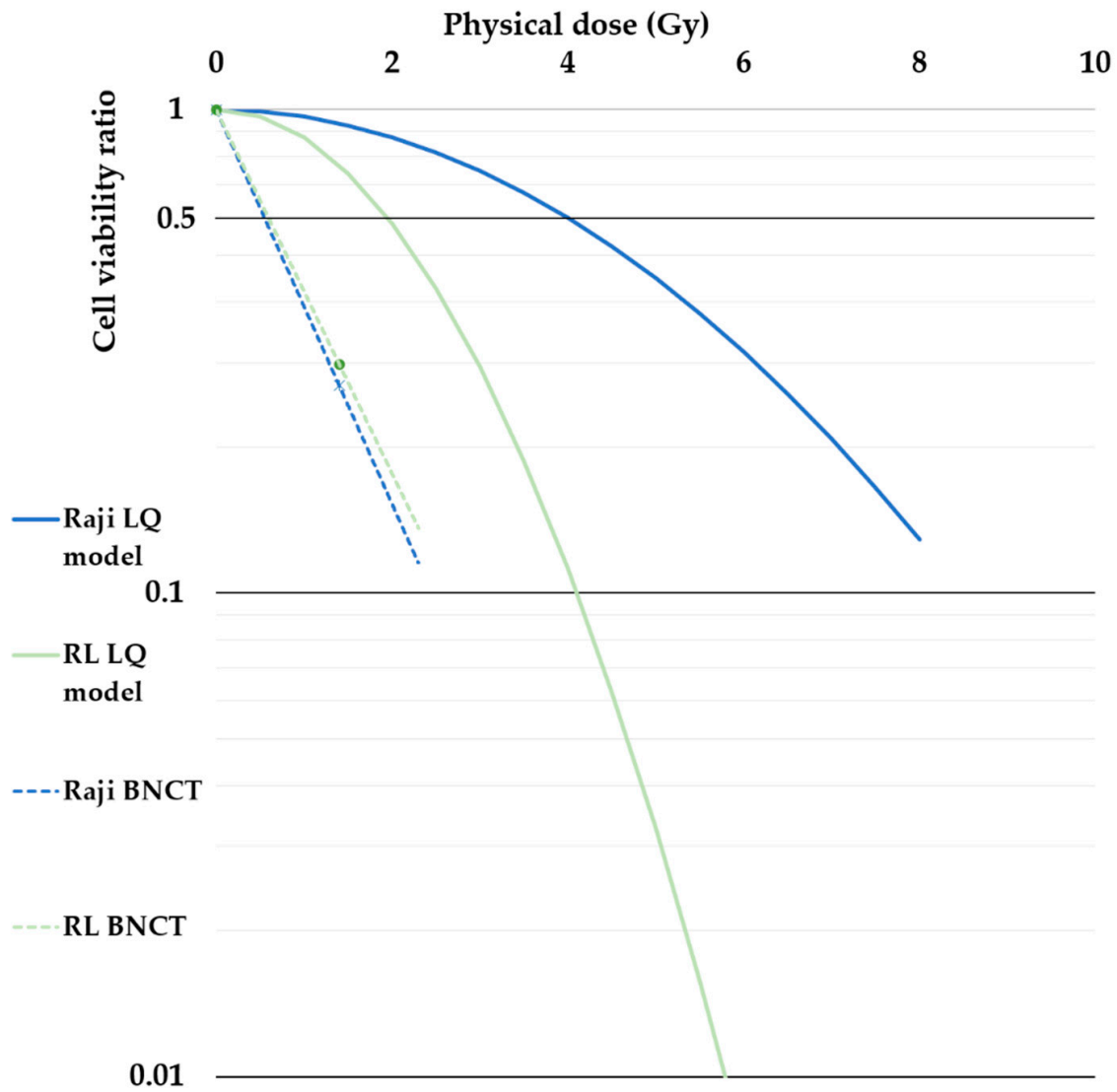

Figure A2. Cell viability ratio after neutron irradiation and photon irradiation fitted to the linearquadratic (LQ) model for Raji and RL lymphoma cells. The physical doses required to achieve the same biological effects as the BNCT group $3 \mathrm{~h}$ after exposure to $5 \mu \mathrm{g} \mathrm{B} / \mathrm{mL}$ of Raji, RL were 4.6 and $2.3 \mathrm{~Gy}$ (cell viability ratio $=0.5$ ). The physical doses for Raji and RL were 8.5 and $4.1 \mathrm{~Gy}$ when the cell viability ratio was 0.1 . The CBE that could be calculated from the LQ model when cell viability ratio $=0.006$ was equal to the $C B E$ value $(\mathrm{Raji}=10.6, \mathrm{RL}=5.6)$ calculated in this study (Raji $=9.5$, $\mathrm{RL}=3.4$ ). 


\section{References}

1. Kawabata, S.; Hiramatsu, R.; Kuroiwa, T.; Ono, K.; Miyatake, S. Boron neutron capture therapy for recurrent high-grade meningiomas. J. Neurosurg. 2013, 119, 837-844. [CrossRef]

2. Ostrom, Q.T.; Cioffi, G.; Gittleman, H.; Patil, N.; Waite, K.; Kruchko, C.; Barnholtz-Sloan, J.S. CBTRUS Statistical Report: Primary Brain and Other Central Nervous System Tumors Diagnosed in the United States in 2012-2016. Neuro-Oncology 2019, 21, v1-v100. [CrossRef]

3. Villano, J.L.; Koshy, M.; Shaikh, H.; Dolecek, T.A.; McCarthy, B.J. Age, gender, and racial differences in incidence and survival in primary CNS lymphoma. Br. J. Cancer 2011, 105, 1414-1418. [CrossRef]

4. Brain Tumor Registry of Japan (2005-2008). Neurol. Neurol. Med.-Chir. 2017, 57, 9-102. [CrossRef]

5. Corry, J.; Smith, J.G.; Wirth, A.; Quong, G.; Liew, K.H. Primary central nervous system lymphoma: Age and performance status are more important than treatment modality. Int. J. Radiat. Oncol. Biol. Phys. 1998, 41, 615-620. [CrossRef]

6. Ferreri, A.J.; Blay, J.Y.; Reni, M.; Pasini, F.; Spina, M.; Ambrosetti, A.; Calderoni, A.; Rossi, A.; Vavassori, V.; Conconi, A.; et al. Prognostic scoring system for primary CNS lymphomas: The International Extranodal Lymphoma Study Group experience. J. Clin. Oncol. 2003, 21, 266-272. [CrossRef]

7. Kruger, P.G. Some Biological Effects of Nuclear Disintegration Products on Neoplastic Tissue. Proc. Natl. Acad. Sci. USA 1940, 26, 181-192. [CrossRef]

8. Miyatake, S.; Kawabata, S.; Hiramatsu, R.; Kuroiwa, T.; Suzuki, M.; Kondo, N.; Ono, K. Boron Neutron Capture Therapy for Malignant Brain Tumors. Neurol. Med. Chir. 2016, 56, 361-371. [CrossRef]

9. Futamura, G.; Kawabata, S.; Nonoguchi, N.; Hiramatsu, R.; Toho, T.; Tanaka, H.; Masunaga, S.I.; Hattori, Y.; Kirihata, M.; Ono, K.; et al. Evaluation of a novel sodium borocaptate-containing unnatural amino acid as a boron delivery agent for neutron capture therapy of the F98 rat glioma. Radiat. Oncol. 2017, 12, 26. [CrossRef]

10. Hattori, Y.; Kusaka, S.; Mukumoto, M.; Ishimura, M.; Ohta, Y.; Takenaka, H.; Uehara, K.; Asano, T.; Suzuki, M.; Masunaga, S.; et al. Synthesis and in vitro evaluation of thiododecaborated $\alpha, \alpha$-cycloalkylamino acids for the treatment of malignant brain tumors by boron neutron capture therapy. Amino Acids 2014, 46, 2715-2720. [CrossRef]

11. Kawabata, S.; Yang, W.; Barth, R.F.; Wu, G.; Huo, T.; Binns, P.J.; Riley, K.J.; Ongayi, O.; Gottumukkala, V.; Vicente, M.G. Convection enhanced delivery of carboranylporphyrins for neutron capture therapy of brain tumors. J. Neuro-Oncol. 2011, 103, 175-185. [CrossRef]

12. Detta, A.; Cruickshank, G.S. L-amino acid transporter-1 and boronophenylalanine-based boron neutron capture therapy of human brain tumors. Cancer Res. 2009, 69, 2126-2132. [CrossRef]

13. Takahashi, Y.; Akahane, T.; Yamamoto, D.; Nakamura, H.; Sawa, H.; Nitta, K.; Ide, W.; Hashimoto, I.; Kamada, H. Correlation between positron emission tomography findings and glucose transporter 1, 3 and L-type amino acid transporter 1 mRNA expression in primary central nervous system lymphomas. Mol. Clin. Oncol. 2014, 2, 525-529. [CrossRef]

14. Yoshida, F.; Matsumura, A.; Shibata, Y.; Yamamoto, T.; Nakauchi, H.; Okumura, M.; Nose, T. Cell cycle dependence of boron uptake from two boron compounds used for clinical neutron capture therapy. Cancer Lett. 2002, 187, 135-141. [CrossRef]

15. Suzuki, M.; Kato, I.; Aihara, T.; Hiratsuka, J.; Yoshimura, K.; Niimi, M.; Kimura, Y.; Ariyoshi, Y.; Haginomori, S.; Sakurai, Y.; et al. Boron neutron capture therapy outcomes for advanced or recurrent head and neck cancer. J. Radiat. Res. 2014, 55, 146-153. [CrossRef]

16. Yamatomo, N.; Iwagami, T.; Kato, I.; Masunaga, S.; Sakurai, Y.; Iwai, S.; Nakazawa, M.; Ono, K.; Yura, Y. Sonoporation as an enhancing method for boron neutron capture therapy for squamous cell carcinomas. Radiat. Oncol. 2013, 8, 280. [CrossRef]

17. Coderre, J.A.; Makar, M.S.; Micca, P.L.; Nawrocky, M.M.; Liu, H.B.; Joel, D.D.; Slatkin, D.N.; Amols, H.I. Derivations of relative biological effectiveness for the high-let radiations produced during boron neutron capture irradiations of the $9 \mathrm{~L}$ rat gliosarcoma in vitro and in vivo. Int. J. Radiat. Oncol. Biol. Phys. 1993, 27, 1121-1129. [CrossRef]

18. Ben Abdelwahed Bagga, R.; Donnou, S.; Cosette, J.; Sautès-Fridman, C.; Aouni, M.; Fisson, S. Mouse models of primary central nervous system lymphomas: Tools for basing funding and therapeutic strategies. J. Neuro-Oncol. 2015, 121, 9-18. [CrossRef]

19. Soussain, C.; Muldoon, L.L.; Varallyay, C.; Jahnke, K.; DePaula, L.; Neuwelf, E.A. Characterization and magnetic resonance imaging of a rat model of human B-cell central nervous system lymphoma. Clin. Cancer Res. 2007, 13, 2504-2511. [CrossRef]

20. Takeuchi, K.; Hattori, Y.; Kawabata, S.; Futamura, G.; Hiramatsu, R.; Wanibuchi, M.; Tanaka, H.; Masunaga, S.I.; Ono, K.; Miyatake, S.I.; et al. Synthesis and Evaluation of Dodecaboranethiol Containing Kojic Acid (KA-BSH) as a Novel Agent for Boron Neutron Capture Therapy. Cells 2020, 9, 1551. [CrossRef]

21. Batchelor, T.; Carson, K.; O’Neill, A.; Grossman, S.A.; Alavi, J.; New, P.; Hochberg, F.; Priet, R. Treatment of primary CNS lymphoma with methotrexate and deferred radiotherapy: A report of NABTT 96-07. J. Clin. Oncol. 2003, 21, 1044-1049. [CrossRef]

22. Ostrom, Q.T.; Gittleman, H.; de Blank, P.M.; Finlay, J.L.; Gurney, J.G.; McKean-Cowdin, R.; Stearns, D.S.; Wolff, J.E.; Liu, M.; Wolinsky, Y.; et al. American Brain Tumor Association Adolescent and Young Adult Primary Brain and Central Nervous System Tumors Diagnosed in the United States in 2008-2012. Neuro-Oncology 2016, 18 (Suppl. 1), i1-i50. [CrossRef]

23. Milgrom, S.A.; Yahalom, J. The role of radiation therapy in the management of primary central nervous system lymphoma. Leuk. Lymphoma 2014, 56, 1197-1204. [CrossRef]

24. Reni, M.; Ferreri, A.J.M.; Villa, E. Second-line treatment for primary central nervous system lymphoma. Br. J. Cancer 1999, 79, 530-534. [CrossRef] 
25. Abrey, L.E.; DeAngelis, L.M.; Yahalom, J. Long-term survival in primary CNS lymphoma. J. Clin. Oncol. 1998, 16, 859-863. [CrossRef] [PubMed]

26. Doolittle, N.D.; Korfel, A.; Lubow, M.A.; Schorb, E.; Schlegel, U.; Rogowski, S.; Fu, R.; Dósa, E.; Illerhaus, G.; Kraemer, D.F.; et al Long-term cognitive function, neuroimaging, and quality of life in primary CNS lymphoma. Neurology 2013, 81, 84-92. [CrossRef]

27. Correa, D.D.; Shi, W.; Abrey, L.E.; Deangelis, L.M.; Omuro, A.M.; Deutsch, M.B.; Thaler, H.T. Cognitive functions in primary CNS lymphoma after single or combined modality regimens. Neuro-Oncology 2012, 14, 101-108. [CrossRef]

28. Caveness, W. Radiation damage to the nervous system. Arch. Neurol. 1981, 38, 787.

29. Suzuki, M.; Masunaga, S.; Kinashi, Y.; Nagata, K.; Sakurai, Y.; Nakamatsu, K.; Nishimura, Y.; Maruhashi, A.; Ono, K. Intra-arterial administration of sodium borocaptate (BSH)/lipiodol emulsion delivers B-10 to liver tumors highly selectively for boron neutron capture therapy: Experimental studies in the rat liver model. Int. J. Radiat. Oncol. Biol. Phys. 2004, 59, 260-266. [CrossRef] [PubMed]

30. Hill, J.S.; Kahl, S.B.; Kaye, A.H.; Stylli, S.S.; Koo, M.S.; Gonzales, M.F.; Vardaxis, N.J.; Johnson, C.I. Selective tumor uptake of a boronated porphyrin in an animal model of cerebral glioma. Proc. Natl. Acad. Sci. USA 1992, 89, 1785-1789. [CrossRef] [PubMed] 